\title{
GESTÃO DE ESTOQUES EM UMA METALÚRGICA DO SETOR DE AUTOPEÇAS
}

\section{INVENTORY MANAGEMENT IN A METALLURGICAL OF THE AUTOMOTIVE INDUSTRY}

\author{
Recebido: 09/09/2015 - Aprovado: 06/11/2015 - Publicado: 29/12/2015 \\ Processo de Avaliação: Double Blind Review \\ Marcos Antonio Maia de Oliveira ${ }^{1}$ \\ Doutor e Mestre em Administração. \\ FATEC - Guarulhos \\ marcos.maia@fatec.sp.gov.br \\ Maiara Maria da Silva \\ Tecnóloga em Logísitca \\ Universidade Anhanguera de São Paulo \\ maiaramary@yahoo.com.br
Winston Aparecido Andrade
Mestre em Administração
FATEC - Guarulhos
wisntonmatematico@gmail.com

\author{
Alexandre Formigoni \\ Doutor em Engenharia de Produção \\ Universidade Braz Cubas \\ a_formigoni@yahoo.com.br
}

\begin{abstract}
RESUMO: O presente artigo tem como objetivo analisar a importância da gestão de estoques em uma metalúrgica, localizada na cidade de Santo André, na Grande São Paulo, visto que a gestão de estoques é fundamental dentro de uma empresa que quer sobreviver nos dias atuais, estudando as principais características e tendências dos métodos utilizados para controle de estoques. Neste estudo de caso foram considerados conceitos básicos para um bom controle, mostrando ferramentas usadas atualmente no mercado, fornecendo dados para compra de material, controle de vendas, peças em estoque, pedidos futuros, MRP, espaço de armazenagem, entre outros uma vez que muitas empresas têm um custo elevado e desnecessário com estoque por não ter conhecimento da real importância deste controle. Percebe-se que a logística da empresa deverá investir em tecnologia, visitando feiras, participando de seminários e capacitando
\end{abstract}

\footnotetext{
1 Autor para correspondência: Fatec - Guarulhos: R. João Gonçalves, 511 - Centro, Guarulhos - SP, 07010-010.
} 
os envolvidos com a gestão de estoques. Assim, a empresa terá um melhor controle de estoque e provável diminuição da compra de material.

PALAVRAS CHAVE: Controle de Estoque; Custos de Estoques; Compras.

ABSTRACT: This article aims to analyze the importance of inventory management in a metallurgical company, located in Santo André city, in Grande São Paulo, since the inventory management is crucial within a company that wants to survive nowadays, by studying the main features and trends in the methods used for inventory control. In this case study the basic concepts for good control were considered, showing tools currently used in the market, providing data for material purchase, sales control, parts in stock, future orders, MRP, storage space, among others once many companies have high and unnecessary cost of stock for not being aware of the real importance of this control. It is felt that the logistics of the company should invest in technology by purchasing the MRP system, visiting fairs and attending seminars. This way, the company will have better inventory control thus consequently decrease the purchase of materials.

KEYWORDS: Inventory Control; Inventory Costs; Purchases.

\section{INTRODUÇÃO}

O gerenciamento de estoque é tema que cada vez mais ganha espaço nas empresas visto que todas elas têm a necessidade de gerenciar seus estoques de forma eficaz, reduzindo os custos, atendendo com qualidade e no tempo certo seus clientes, tornando-se assim, competitivas, com menos custos no mercado atual.

Trata-se de uma empresa com grande volume de estoque que, aparentemente representa prejuízo, pois é onde fica o capital parado e, como não há um controle eficaz, muitas vezes acaba-se produzindo e comprando em excesso. Para melhor controle é necessário um sistema integrado que forneça dados atuais a toda empresa para que os setores responsáveis se programem. Um sistema deve facilitar o trabalho de toda a empresa otimizando o tempo, integrando todas as áreas da empresa para não haver erros, evitando assim, desperdícios.

São abordados neste artigo, conceitos e ferramentas que poderão ajudar no controle e planejamento dos fluxos de materiais dentro da empresa, como Kanban, Just in time e Curva ABC.

\section{FUNDAMENTAÇÃO TEÓRICA}

\subsection{ESTOQUES}


Na definição de Chiavenato (2005) gestão de estoques aborda todos os recursos armazenados, tanto para a transformação, quanto para a venda. Em muitas empresas é uma forma de se proteger quanto às dificuldades do processo interno (produção) e externos (fornecedores) e quanto às variações nas demandas.

De acordo com Ching (1999) essa visão de estoque superior ao necessário acarreta vários problemas para a empresa tais como: custos mais altos de manutenção de estoque; falta de tempo na resposta ao mercado e risco de inventários tornarem-se obsoletos. O controle de estoque tem uma grande influência na rentabilidade da empresa, pois o dinheiro que fica parado poderia ser utilizado para outros projetos ou até mesmo em fundos de investimento.

Há várias razões para as oscilações das taxas de fornecimento e demanda em qualquer ponto da operação, não importa o que é armazenado, o estoque sempre existirá, pois existe um desequilíbrio entre o fornecimento e a demanda. Slack (2007) classifica cinco tipos de estoque: estoque de segurança, estoque de cíclico, estoque de desacoplamento, estoque de antecipação e estoque no canal.

Segundo Dias (1995) o estoque de segurança ou estoque isolador é um estoque mínimo para compensar as incertezas na demanda, no fornecimento e no processo, compensando possíveis problemas de alguns fornecedores e transportes. Ainda, segundo o autor, o estoque cíclico ocorre quando há gargalos produtivos em algum estágio das operações, os quais podem ocorrer em um ou mais estágios da linha de produção.

Estoque de desacoplamento é quando o arranjo físico do processo não permite que o produto seja produzido em linha, portanto ele é produzido em um departamento ou em áreas similares ao processo. Dessa forma, quando a operação se encontra pronta, a mesma ficará aguardando a programação para o próximo estágio. Este procedimento é usado normalmente para atender eventos sazonais, para compensar atrasos de fornecedores e aumento de demanda. Portanto, o produto é produzido antecipadamente para que se possa atender no prazo solicitado pelo cliente (MOURA, 2004).

Para Ching (1999) estoques no canal de distribuição normalmente se referem ao estoque em trânsito, usado quando o produto sai do centro de distribuição para o cliente. Neste momento, o material passa a ficar indisponível para outro consumidor. 
Estoque ativo é todo estoque analisado e planejado antecipadamente, sendo destinado a uma utilização em Produção; Produtos; Manutenção; Produtos Acabados e Materiais Administrativos. O estoque inativo é o estoque em excesso e inutilizado, produzido por alterações de programas, falhas de planejamento, mudanças nas políticas de estoque ou peças obsoletas. (MALAGOLI, 2005).

\subsection{CUSTOS DO ESTOQUE}

Custos logísticos são os custos que a empresa gasta com sua logística total, os quais são importantes na empresa, pois normalmente estes só não são mais altos do que o custo do produto. Por isso a necessidade de se controlar bem esses custos, pois é através desse controle que reside toda a saúde da empresa (SLACK, 2007). Existem três classes gerais de custos, para uma política eficaz de estoque: Custo de Aquisição, Custos de Manutenção e Custos de falta de estoque.

\subsubsection{Custos de aquisição}

Na definição de Ballou (2013) esse custo é associado à aquisição e reposição do estoque. Quando se solicita uma reposição de estoque há uma grande variedade de custos em todo o seu processo, tais como preparação, transmissão e o pedido de compras, os quais podem incluir o custo para a preparação na produção (setup) ou do manuseio para atender o lote solicitado e até mesmo do transporte, caso não haja desconto na compra do produto. Quando a empresa tem sua própria matéria prima os custos são alterados para mostrar os custos de toda a preparação do processo.

\subsubsection{Custos de manutenção}

Segundo Slack (2007) estes são custos necessários para manter mercadorias armazenadas por um determinado período e podem ser classificados em quatro tipos:

- Custos de espaço: são cobrados pelo uso do espaço do prédio em que o produto está estocado. Quando o espaço é alugado as taxas são cobradas pelo peso e tempo em que o produto ficará estocado; já quando o espaço é próprio ou contrato os custos são determinados anteriormente. 
- Custos de capital: poderão representar $80 \%$ dos custos totais de estoque, sendo derivados do custo do dinheiro parado em estoque.

- Custos dos serviços de estocagem: representam uma parte pequena dos custos totais da manutenção. São seguros feitos para garantir a perda causada por roubos, tempestades e/ou incêndios.

- Custos dos riscos de estocagem: compõem a última categoria dos custos de manutenção e podem ser estimados como perda do valor do produto ou custo do retrabalho.

\subsubsection{Custos da falta de estoque}

Para Ching (1999), os custos da falta de estoque ocorrem quando um pedido não pode ser atendido por falta de peças no estoque. Podem ser classificados em dois tipos:

- Custos de venda perdida ocorrem quando o cliente solicita o produto, porém como este não se encontra no estoque, o mesmo opta pelo cancelamento do pedido. Com isso o custo é a venda não concretizada, ou seja, o lucro não obtido.

- Custos de pedidos em atraso ocorrem quando há atraso na solicitação do cliente, porém o mesmo aceita esperar o atendimento do pedido. Esse atraso pode gerar custos adicionais, como por exemplo transportes adicionais para entrega do item solicitado.

\subsection{PREVISÃO DE DEMANDA}

Para Dias (1995), previsão de demanda é a base do planejamento estratégico da produção, finanças e vendas da empresa, sendo indispensável para a sua organização, pois com ela os gestores planejam quando, quanto e quais produtos deverão ser comprados e produzidos. Este procedimento consiste em enviar aos seus fornecedores e clientes programas com as solicitações futuras de pedidos.

Existe um grande esforço para desenvolver métodos para controlar a demanda, tais como pesquisas, opinião de pessoas entendidas, projeção de vendas passadas e até mesmo uma média de vendas no período (BALLOU, 2013). 
Segundo Slack (2007) a demanda pode ser classificada em duas categorias: quantitativas e qualitativas. Conforme Tubino (2009), as técnicas quantitativas consistem em analisar dados passados para projetar demandas futuras, podendo ser divididas em dois grupos: Séries temporais e Técnicas baseadas em correlações. As séries temporais não sofrem influências de outras variáveis e relacionam os dados históricos do produto com o tempo, sendo o método mais simples e usual de previsões) e as técnicas baseadas em correlações procuram associar os dados históricos com uma ou mais variáveis que tenham alguma relação com a demanda do produto.

Para Slack (2007) as técnicas qualitativas são baseadas na opinião de especialistas nos produtos ou no mercado, tais como executivos das principais áreas da empresa, vendedores ou até mesmo clientes. Normalmente elas são usadas quando na introdução de um produto novo, onde não existam dados matemáticos para mensurar ou até mesmo quando o panorama econômico for instável, fazendo com que os dados fiquem rapidamente obsoletos.

Para Ballou (2008) uma das melhores maneiras de classificar o estoque é a natureza da sua demanda, a qual pode ser permanente, sazonal, irregular, em declínio e derivada:

- Demanda Permanente: Requer abastecimento contínuo ou periódico, estabelecimento de lote econômico, prazos de abastecimento bem definidos e previsão de demanda por item.

- Demanda Sazonal: Picos de demanda em épocas conhecidas e previsão acurada do nível futuro de demanda.

- Previsão de Irregular: Previsão de vendas imprecisas, dificultando a programação.

- Demanda em Declínio: Diminuição periódica do nível de estoque, até a sua extinção total.

\subsection{FERRAMENTAS PARA A GESTÃO E CONTROLE DE ESTOQUES}

\subsubsection{Just in time}


Para Ching (1999) Just in time (JIT) é uma filosofia criada no Japão para redução de desperdícios no processo de fabricação, atendendo a qualidade e a eficiência e utilizando o mínimo de recursos, sem desperdícios. Assim o JIT leva estoque mais baixos, a custos menores. Mondem (1984) define o Just in Time como: "Produzir as unidades necessárias, em quantidades necessárias, no tempo necessário”. Desta forma, verificamos que o sistema Just in Time produz somente o necessário, através da disciplina e trabalho em equipe.

A implantação do sistema Just in Time necessita de uma boa comunicação entre cliente e fornecedor, na qual ambos devem ser flexíveis. Em cada parte do processo, produz-se somente o necessário, evitando assim, estoques intermediários. $\mathrm{O}$ JIT requer os seguintes princípios:

- Qualidade: precisa ser alta, pois problemas com qualidade reduzirão todo o processo de materiais;

- Velocidade: é imprescindível para atender os clientes diretamente conectados com a produção;

- Confiabilidade: necessária para que se tenha um fluxo rápido de produção;

- Flexibilidade: necessária para que se ter lead time curtos, produzir pequenos lotes e efetuar trocas rápidas;

- Compromisso: é essencial o compromisso entre fornecedor e cliente; o material deverá chegar ao momento acordado para não haver problema de desabastecimento.

O sistema JIT puxa a produção ao longo do processo de acordo com a demanda real, no exato momento, evitando assim, acúmulo de estoque. Desse modo, o fornecedor deve seguir a filosofia da montadora, exigindo planejamento e comunicação eficiente, evitando falhas.

\subsubsection{Kanban}

Outra ferramenta utilizada é o sistema Kanban. Para Correa (1997) os cartões Kanban informam quanto e quando será produzido um produto, assim o planejamento será realizado sob encomenda, ou seja, puxado e não empurrado. O cartão Kanban de 
produção ou montagem é chamado de Kanban em processo, sendo usado para autorizar a produção dos itens e determinar os lotes dos mesmos, conforme exemplo na figura 1.

Figura 1 - Cartão kanban de produção.

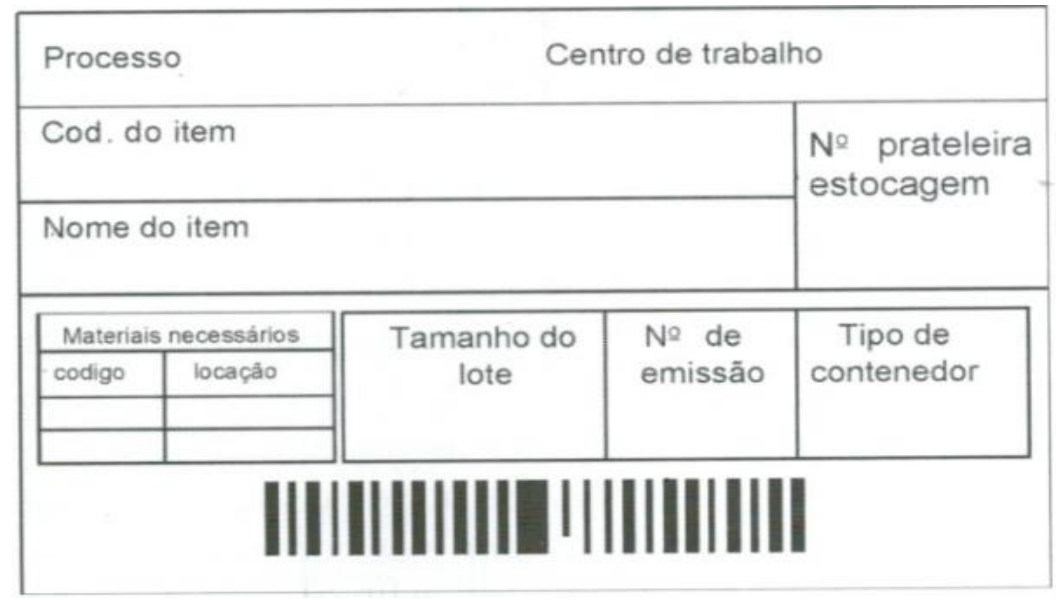

Fonte: Tubino (2009)

Existe também outro cartão, chamado de cartão Kanban de transporte, conforme figura 2, o qual permite que haja movimentações dos itens dentro da fábrica e que estas sejam adicionadas no sistema puxado, assim, o fluxo de informações para a movimentação ou para a produção, se dá sem a interferência do PCP (CORREA, 1997).

Para Moura (2004) tanto no Kanban de produção, quanto no Kanban de movimentação, devem constar apenas informações indispensáveis para movimentação dos itens, ou seja:

- $\quad$ Descrição do item, com seu código;

- $\quad$ Especificação de onde o item é produzido;

- $\quad$ Especificação de onde o item será consumido;

- Tamanho do lote que será movimentado;

- $\quad$ Tipo de container para esse item;

- $\quad$ Número de emissão deste cartão em relação ao número total de cartões de movimentação para esse item;

- Código de barras que, ao ser lido, adiantará o fluxo de informações do banco de dados do ERP. 
Figura 2 - Cartão kanban de movimentação.

\begin{tabular}{|c|c|c|c|}
\hline \multicolumn{3}{|l|}{ Cod. do item } & \multirow{3}{*}{$\begin{array}{l}\text { Centro de trabalho } \\
\text { fornecedor } \\
\text { Localização no } \\
\text { estoque }\end{array}$} \\
\hline \multicolumn{3}{|l|}{ Nome do item } & \\
\hline \multirow[t]{2}{*}{$\begin{array}{l}\text { Tamanho do } \\
\text { lote }\end{array}$} & \multirow[t]{2}{*}{$\begin{array}{l}\mathrm{N}^{\mathrm{d}} \text { de } \\
\text { emissão }\end{array}$} & \multirow[t]{2}{*}{$\begin{array}{c}\text { Tipo de } \\
\text { contenedor }\end{array}$} & \\
\hline & & & \multirow{2}{*}{$\begin{array}{l}\text { Centro de trabalho } \\
\text { cliente } \\
\text { Localização no } \\
\text { estoque }\end{array}$} \\
\hline & & . & \\
\hline
\end{tabular}

Fonte: Tubino (2009)

De acordo com Tubino (2009) ainda existe o Kanban de fornecedor, conforme figura 3, o qual normalmente é usado para acionar reposições de itens comprados. Esse sistema simplifica e racionaliza todas as atividades da logística de reposição visto que os fornecedores parceiros ficam previamente autorizados a repor os itens com os lotes padrões na linha do cliente, a partir do recebimento dos cartões Kanban.

Figura 3 - Cartão kanban de fornecedor.

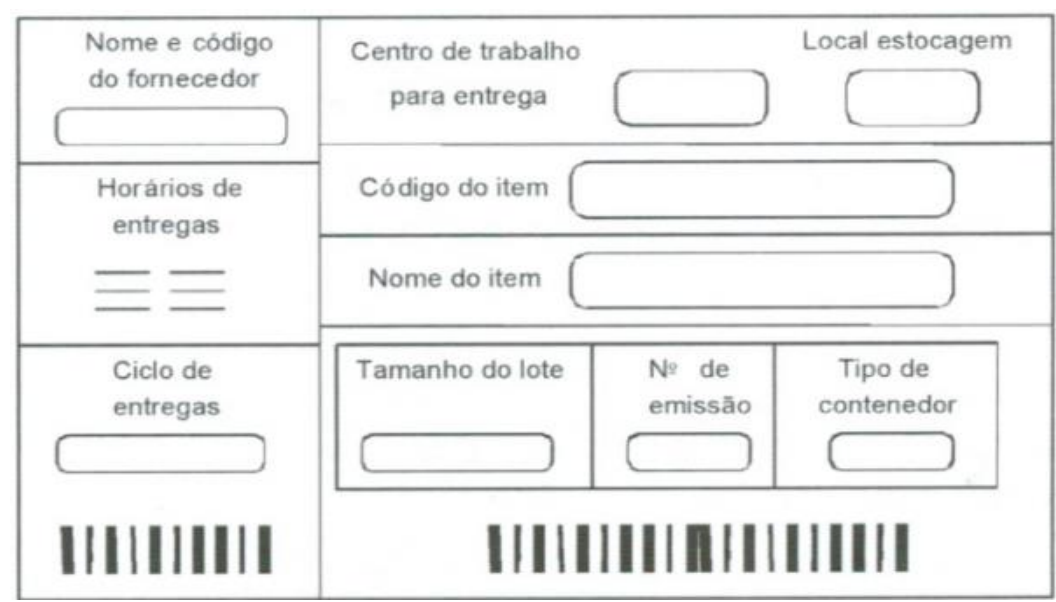

Fonte: Tubino (2009)

\subsubsection{Curva $\mathrm{ABC}$ e MRP (Material Requirement Planning)}

Segundo Ballou (2008) a curva ABC é uma ferramenta para identificar os itens que precisam de mais atenção, pois alguns são mais rentáveis ou ainda os clientes exigem um melhor nível de serviço. A Curva ABC baseia-se no fato de que $20 \%$ dos 
clientes da empresa representam $80 \%$ das vendas dos produtos. De acordo com Ching (1999), após os produtos serem ordenados pela importância, as classes da curva ABC podem ser representadas da maneira a seguir:

- Classe A: itens a serem tratados com mais importância pelos administradores da empresa;

- Classe B: Itens que devem ser tratados em situação mediana pelos administradores;

- $\quad$ Classe C: Itens com menos importância.

Desse modo, com essa análise os gerentes poderão concentrar seus esforços nos produtos que realmente têm relevância. O sistema MRP é um modelo de controle baseado nos cálculos das necessidades de materiais e foi desenvolvido com o objetivo de aproveitar a capacidade da armazenagem e o processamento de dados, tendo surgido com a introdução da informática para ajudar na programação da produção (TUBINO, 2009).

Esse sistema é capaz de planejar todas as necessidades de materiais de acordo com as estruturas do produto e roteiro das operações, período a período, definindo a quantidade e o tempo exato para utilização dos produtos.

\section{METODOLOGIA}

A empresa objeto deste estudo de caso solicitou não ter sua identidade revelada, contudo forneceu os dados e informações e apoiou a realização do mesmo, tendo este, características tais que poderão ser aplicadas a demais casos, em semelhantes situações.

\section{ESTUDO DE CASO}

\subsection{HISTÓRICO DA EMPRESA}

Fundada em 1982 no município de Santo André, a Metalúrgica ABC LTDA iniciou-se com a produção de fluidos de freios automotores, passando a fabricar componentes estampados para a indústria automotiva já no ano seguinte. Esta empresa é constituída de capital nacional e conta com uma equipe de 430 colaboradores distribuídos em quatro plantas, Unidade I (matriz) localizada em Santo André e Unidade II, III e IV (filiais) em Mauá, sendo esta última o foco desta pesquisa. A Unidade IV só 
iniciou suas atividades no ano 2008, com médio porte e conta com equipamentos convencionais e automatizados para a produção de seus estampados e conjuntos soldados para a rede automobilística do país.

A cultura organizacional da Metalúrgica $\mathrm{ABC}$ expressa o compromisso com a ética no relacionamento com todos os seus clientes, funcionários, acionistas, fornecedores, poder público, comunidade e sociedade em geral, ou seja, com todos seus stakeholders, público estratégico. Tem aplicação obrigatória entre os colaboradores da empresa e deve servir de referência para os parceiros da mesma.

A empresa espera que seu código de conduta inspire relações integras, imparciais, transparentes e de respeito às pessoas, à diversidade e ao meio ambiente. Para conhecer, analisar e resolver qualquer questão referente à cultura organizacional, a empresa garante a confiabilidade das informações, preservando a identidade das pessoas envolvidas.

\subsection{DEMANDA DO MERCADO}

Para Vasconcellos (2011), demanda é o número de bens ou serviços que os consumidores aderem, num determinado período de tempo. A procura depende de inconstantes escolhas que entusiasmam o consumidor. Tudo pode ser relativo às principais preferências e hábitos do indivíduo. A Metalúrgica $\mathrm{ABC}$ fabrica estampados para carros, à medida em que varia o preço dos produtos, não se deve considerar as variações dos preços de outros produtos. São bens complementares, aqueles que o consumidor deseja consumir conjuntamente. Como se pode observar, na tabela 1 , há alternativas de preço de um único produto de acordo com demanda do primeiro semestre de 2014.

Tabela 1: Demanda diária da bobina de aço

\begin{tabular}{ll}
\hline Preço $(\mathrm{R} \$)$ & Quantidade demandada \\
\hline 24,05 & 4500 \\
26,05 & 4300 \\
27,01 & 4100 \\
\hline
\end{tabular}

Fonte: Empresa foco do trabalho (2014). 


\subsection{LAYOUT DA EMPRESA}

O layout da empresa tem as características de um layout funcional, quantidades de produtos e de materiais, sequências de operações e de montagem, espaço necessário para cada equipamento, incluindo o espaço para a movimentação do operador, estoques e manutenção, e informações sobre recebimento, expedição, estocagem de matériasprimas, produtos acabados e transportes. É possível observar mais detalhadamente a forma de funcionamento da linha, a seguir.

Figura 4: Vista geral de linha de prensas da Metalúrgica ABC.

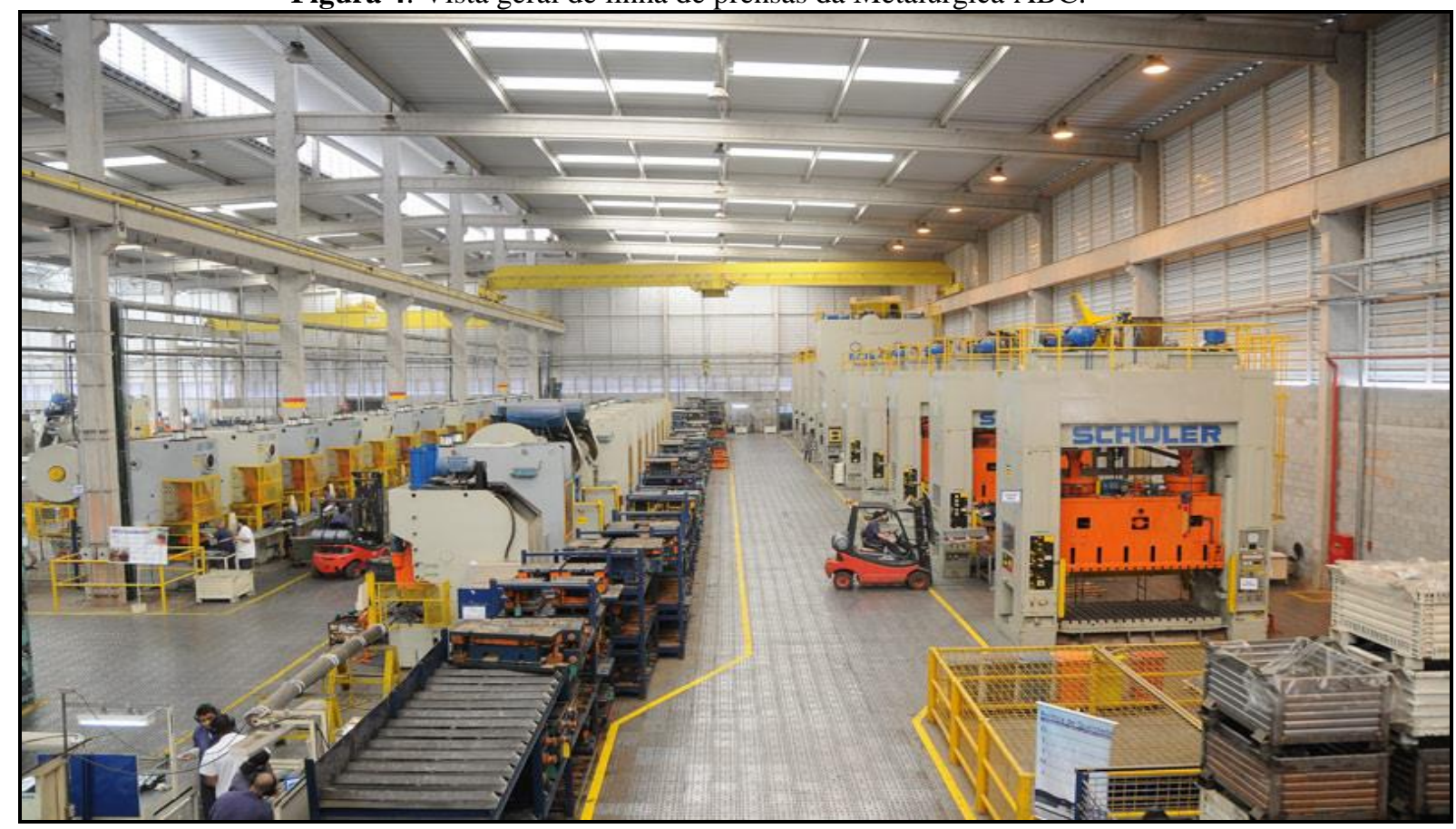

Fonte:departamento de RH da empresa).

\subsection{FLUXO DE ENTRADA E ARMAZENAGEM DAS PEÇAS}

A empresa analisada possui setor para o armazenamento dos estoques, o qual encontra-se estruturado da seguinte forma: almoxarifado (matéria-prima, bobinas, chapas e materiais plásticos) e insumos (parafusos, pinos e porcas), sendo que cada um desses itens possui um local de armazenamento específico. A mesma conta ainda com um setor de embalagem, onde ficam acomodados os produtos acabados, advindos do setor produtivo, para serem embalados até a solicitação do cliente, e o setor de 
expedição onde os produtos acabados e embalados aguardam para ser destinados aos clientes.

Antes o controle de estoques era feito em planilha Excel, contudo hoje ele é realizado através de um sistema de informações denominado PROTHEUS. Este sistema concentra todas as informações, promovendo a interatividade de planejamento, programação e controle da produção (PPCP) dentro do sistema, facilitando assim, a visualização de todos que, de alguma maneira, utilizam as informações do estoque como base para compras atuais e futuras, pedidos de vendas, custo financeiro do estoque e balanço fiscal.

Para Martins e Laugeni (2005), produtividade tem como uma de suas finalidades reduzir custos de manufatura e integração de suas fases, dentro do clico de produção. O modal mais utilizado para entrega de seus produtos é o modal rodoviário, uma vez que a maioria dos seus produtos são transportados pelo sistema Milk Run "corrida do leite", que tem este nome porque - antigamente o transportador que passava em várias fazendas- retirava o leite e fazia a sua entrega a empresas de laticínio, sem cruzar o caminho na rota (Ching, 1999). Cada cliente, por sua vez, tem o seu horário e dia especéfico para coleta de material visto que $80 \%$ das entregas são de responsabilidade dos clientes

\subsection{Setor de análise}

A produção e o estoque de produtos estão entrelaçados em suas atividades, afinal as peças que saem da linha de produção são armazenadas até a data de entrega ao consumidor final. Segundo Messias (1989) o armazenamento é necessário para reduzir custos e atender melhor os clientes.

Na empresa há uma grande quantidade de peças armazenadas já que a procura não é mais tão grande devido à crise financeira que estão enfrentando as empresas fabricantes de automóveis. A demanda está abaixo do programado e a empresa não fez uma programação adequada para a fabricação de seus produtos, como se pode observar, na figura 5, o que pode ser reflexo da falta capacitação para o correto uso da ferramenta adequada para a gestão do estoque, isto é, foram desconsiderandos os efeitos macroeconômicos que podem ter afetado as previsões anteriores. 
Figura 5: Estoque de peças acima da quantidade em função da demanda.

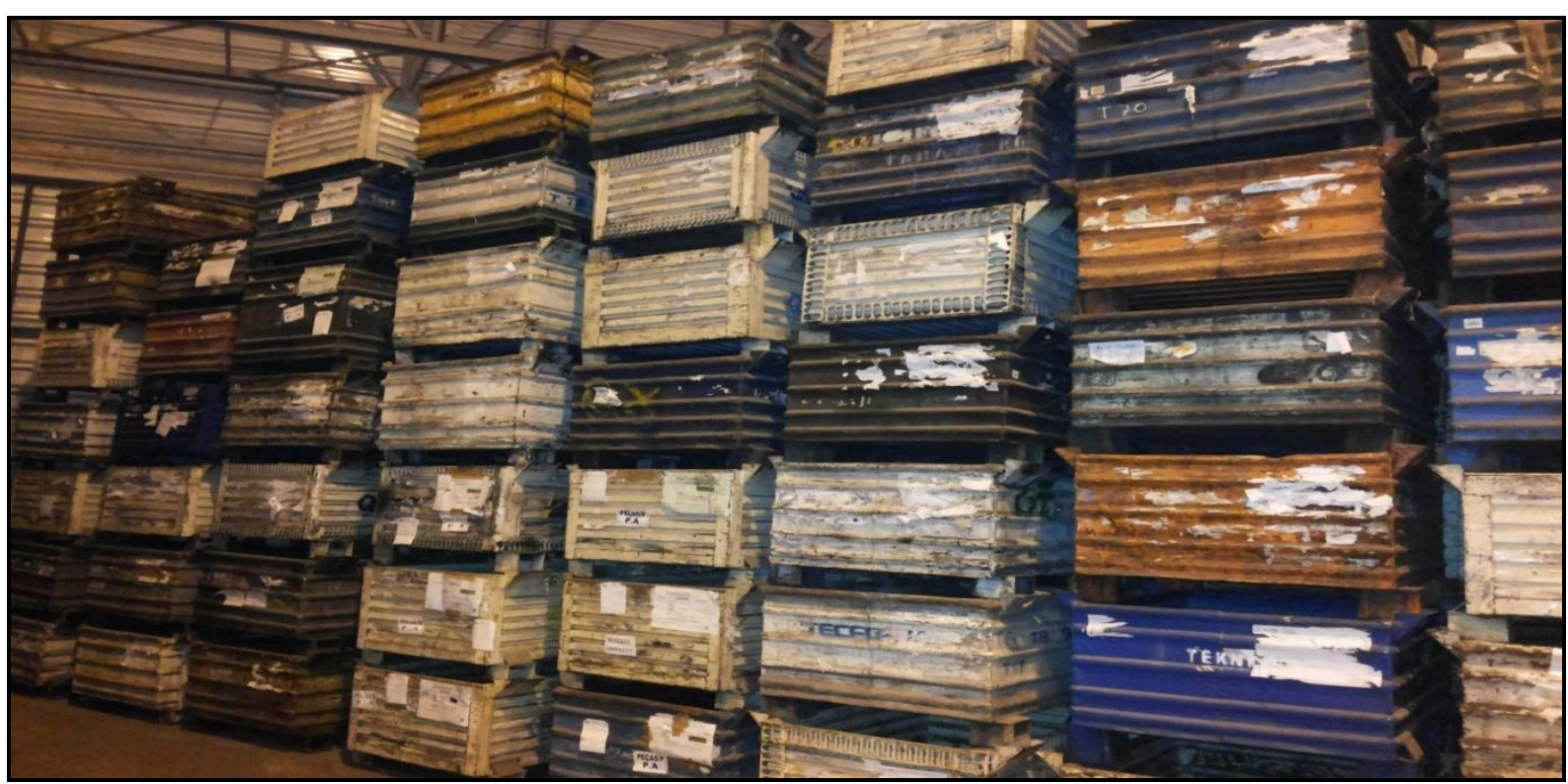

Fonte: Metalúrgica $\mathrm{ABC}$.

A Área de organização de peças é identificada com o nome de cada cliente, tais como General Motors, Ford ou Volkswagen.

\section{CONSIDERAÇÕES FINAIS}

A situação do mercado automotivo vem sendo afetada com a baixa procura e, além disso, a gestão de estoques inadequada pode estar acarretando o acúmulo de peças em diversos setores. A empresa estudada está em mudança para adaptar-se ao cenário econômico do país, por isso vem se reestruturando e entende que precisará investir na equipe e na capacitação de seus colaboradores para que haja a oportunidade de ampliar sua capacidade e usar melhor seus recursos, desenvolvendo produtos diferentes.

No que se diz respeito à Logística, a empresa deverá investir em tecnologia, visitando feiras, seminários e investindo em internet, visto que esta já deu o primeiro passo, com o uso do sistema de gestão empresarial, o PROTHEUS. Isso possibilitará que a empresa tenha um melhor controle de estoque e diminua a compra de material, pois a logística será feita de maneira mais segura pelo MRP visto que o que antes era feito em planilha Excel e ficava concentrado nas mãos de poucas pessoas, com o MRP poderá ser visualizado por toda a empresa. 


\section{REFERÊNCIAS}

BALLOU, Ronald $H$. Gerenciamento da cadeia de suprimentos / logística empresarial. 5. Ed. Porto Alegre (RS):Bookman, 2008.

BALLOU, Ronald H. Logística Empresarial. Ed. São Paulo : Atlas, 2013.

CHIAVENATO, I. Administração de Materiais: uma abordagem introdutória. Rio de Janeiro. $3^{\text {a }}$ reimp. Elsevier, 2005.

CHING, H.Y. Gestão de estoques na cadeia de logística integrada supply chain. 2. Ed. São Paulo: Atlas, 1999.

CORRÉA, H.L. Planejamento, Programação e Controle da Produção MRP II, ERP: Conceitos, uso e implantação. 2. Ed. São Paulo (SP): Atlas, 1997.

DIAS, M.A.P. Administração de Materiais: Uma Abordagem Logística. 4 São Paulo Atlas, 1993.

MALAGOLI, J.G. Controle de Estoque. Monografia (Graduação em Administração) Centro Universitário Salesiano Auxilium de Lins, 2005.

MESSIAS, S. B. Manual da Administração de Materiais Planejamento e Controle dos Estoques. 9. Ed. São Paulo: Atlas, 1989.

MOURA, C.E. Gestão de Estoques. Editora Ciência Moderna, 2004.

SLACK, Nigel. Administração da Produção. 2. Ed. São Paulo: Atlas, 2007.

TUBINO, Dalvio Ferrari. Planejamento, Programação e Controle da Produção. 2. Ed. São Paulo: Atlas, 2009.

VASCONCELLOS, Marco Antonio Sandoval de; GARCIA, Manuel Henriquez. Fundamentos da economia.4 ed. São Paulo: Saraiva, 2011. 